\title{
$\mathrm{COM}$
}

\section{Simone Rödder}

\section{Abstract}

Introducing the

Hamburg

"visiting artist

researcher"

project
This set of comments reports experiences from a recent "science-meets-arts"-project in Germany, in which students from the University of Fine Arts in Hamburg (HFBK) shared day-to-day life in climate research groups for several months. The project was envisioned as a process of mutual inspiration with the aim of producing a joint exhibition and symposium at the end. This paper introduces the project as well as the subsequent commentaries and also presents some of my own observations as project manager.

Between February and October 2014, seven undergraduate students of the University of Fine Arts in Hamburg (HFBK) came to the University of Hamburg's Cluster of Excellence "Integrated Climate Analysis and Prediction" (CliSAP) as "visiting artist researchers". They had been carefully selected, out of 37 applicants, on the basis of their artistic vita and a project sketch. Likewise, 14 CliSAP research groups competed to host an artist. The project was set up in the tradition of placing artists in scientific environments to create an atmosphere of mutual inspiration. The aim was to finish with a joint exhibition and symposium to make both art products and exchange processes accessible to a broader audience. Throughout the project, the educational context in which the project was embedded at the HFBK played a role in addition to the science-art encounter. The group met regularly with art school professor Friedrich von Borries and me to discuss their experiences and progress.

This set of comments reflects on what happened when art met climate science in Hamburg, offering views from several participants in the project. They range from meteorologist Frauke Feser, who hosted two artists in her storm studies group, to the complementary account of artist researcher Laura Reichwald, who was hosted by a group of theoretical meteorologists originally to investigate the generation of scientific ideas and who eventually ended up filming on Mount Etna. It entails observations by cultural anthropologist Werner Krauß and thoughts on the value of welcoming artists in research centres by climate scientist Hans von Storch as well as the account of an art school professor, Friedrich von Borries who reflects on the roots of "artistic research". An essay by sustainability scientist Sacha Kagan concludes the set and opens up the Hamburg experience to envision some radical potential for sci-art transdisciplinarity. In the following, this paper introduces the project as well as the subsequent commentaries. My own role was that of project manager and I will weave in observations and comments throughout the text. 
“Understanding

Climate Science in Interaction"
The "visiting artist researcher" programme was part of the broader activity "Understanding science in Interaction" (USI), which is affiliated with the CliSAP cluster and reflects doing interdisciplinarity in climate science from a Science and Technology Studies' perspective. USI has a research component and a component, which came to be known as "in reach", and which aims to stimulate reflexivity among climate researchers. The "science meets art" project was part of this effort. As USI's first flagship project, the visiting artist researchers were subject to a range of expectations.

In many climate scientists' view, the major goal of having artists visiting labs was to challenge contemporary discourses on climate science, climate policy and climate communication. Depending on their own understanding of the science-policy-public nexus, the artistic intervention was imagined more along the lines of producing climate visualisations for science communication purposes - such as producing banners for outreach events or marine paintings of a research vessel - or as an irritation to mainstream opinions in climate science, which run the risk of dogmatism and alarmism. In his comment, Hans von Storch details the latter view, arguing that artists can become "therapists" for climate researchers by questioning the taken-for-granted. From the artistic side, there were no less strategic motivations to collaborate with a research university. Friedrich von Borries describes several of these motives, including a profound impact of the Bologna process on the governance of art schools, and the funding environment for art and research. In their reliance on tax money and a need for accountability thereof, (art school) art and science find common ground. Reviewing the roots of artistic research, however, von Borries argues that it is not mutual instrumentalisation but an overemphasis on this issue that is a concern with regard to sci-art collaboration, as it may obstruct "the view of what is essential in any research practice - be it scientific or artistic: the gain in insight, the openness to the unexpected, the willingness to call into question everything - including itself".

There is wide agreement in the field that there is something to be gained in encouraging artists and scientists to collaborate. Where to look for this value, however, is open to debate (and further research). While many argue that both artists and scientists can learn from one another [e.g., Reichle and Rösl, 2010; Wienroth and Goldschmidt, forth], there is a widespread feeling that an impact on artistic production is more straightforward and likely to be achieved. A first hypothesis of our project, therefore, was that the art students would benefit in their personal and professional artistic development from being placed in a scientific environment. But to add a piece of work to an art student's portfolio didn't fully justify passing on funding from climate to artistic research. Obviously, the hope was that the artistic intervention would also activate reflexivity among CliSAP researchers. So a second hypothesis was that the artistic intervention would facilitate the integrated approach driven by the cluster and challenge some of the taken-for-granted assumptions in climate science and policy. Namely Hans von Storch saw a role for the artist researchers in his long-term concern with exposing the social in the scientific process and questioning the authority of scientific knowledge claims [see e.g., Stehr and von Storch, 1995]. In his comment in this volume, he points to how individual creativity in science can be limited by what Ludwik Fleck has described as schools of thought ("Denkkollektive"). In the case of the climate community, which is engaged in a highly politicised discourse on the 
man-made nature of global warming, von Storch sees a particular need to widen the scope beyond alarmist discourses.

Another body of literature on science-art-interaction emphasises that the "primary value of partnerships lies in a process - the way they work — rather than the end product" [Webster, 2006, p. 77; Wienroth and Goldschmidt, forth]. For cultural anthropologist Werner Krauß, the most fascinating aspect in this process was the occurrence of "self-identification through the other", which in his view happened to both, artists and researchers. In his comment, he describes how artists and scientists approach one another, experience "cultural shocks" or "social death" and subsequently sheer off to safe-guard their own identity. His ethnography of the project fits in nicely with what meteorologist Frauke Feser experienced with the two artist researchers that joined her storm group at the Centre for Materials and Coastal Research of the Helmholtz-Zentrum Geesthacht (HZG). She reports her initial inertia with regard to the project's announcement and her increasing interest in a dialogue between diverging perspectives that turned out to be "more interactive than I had expected". Deep immersion of the visiting artist researchers into the atmosphere of the scientific research environment with its constant data production, discussion, career development, and networking was characteristic of the first phase of the project, as has been observed in other 'artists in labs' projects [Stettler, 2010, p. 36]. Feser's account gives evidence of profound mutual respect that encouraged conversations on topics as diverse as climate visualisation and career challenges in science and arts. But she also noticed a phase (stage 4, p. 4) where the artists "secluded themselves to take in the flood of information and impressions".

Immersion and subsequent distancing happened in all cases. The artists regarded observations, interview data and conversations as material, and with this material, they went back to their art school. Rather than discussing their work with the scientists - which all of the artists reported to hate doing - they discussed their material with their fellow students, teachers and friends. Class colleagues at the HFBK were their peers, and their studios and offices the place where their research material was decontextualised from its scientific origin and reassembled and synthesised in artistic terms. This is exemplified in Laura Reichwald's comment. From the perspective of participating artist researcher, she describes how she first immersed herself in the scientific world, including reading popular and specialist literature and interviewing scientists. Following immersion, however, she "felt the urge to take a step back to put some distance between me and 'my' field of research. In just four months, I had lost the ability to be an outside observer and to have an artistic view on things." (p. 2). Her stepping back became visible in a full change of plans - rather than investigating how ideas are generated in the scientific mind, she settled for a visual analogy of stone and skin as fragile covers of man and Earth, respectively.

Regarding the artistic intervention in a scientific environment, Werner Krauß emphasises the similarity of the artists' role to his role as long-term ethnographer of climate science in the Hamburg area. Just as social scientists and humanists, the artists focussed on science as a social practice. In their artistic recontextualisation, they link human sentiment and material sediment in an innovative way, he argues. Krauß was particularly pleased, when the rather sober project discussions finally approached the public construct of "dangerous climate change" at the occasion of 
the final symposium in October. Sparked by a climate fiction author's doom scenario, the Hamburg scientists as well as the artists had to finally acknowledge the broader political context of their friendly encounters. Sacha Kagan, who was only introduced to the project at this very event, made this presumable apolitical nature of project and products his main point of criticism. In his essay in this volume, he brings forward a strong case for coupling the arts to science and technology. Critically reframing the prevailing discourse, he suggests that "moving beyond the traditional boundaries of social systems, artistic research and climate science may engage in a shared transdisciplinary learning process. They may communicate with the rest of society by engaging with others to develop 'spaces of possibilities', thus nurturing the creative resilience of communities."

\section{Concluding remarks on concluding the project}

From the beginning, we envisioned an exhibition of the artwork and a scientific symposium, assuming that the arts as well as the sciences only acknowledge a contribution if it is made public. The exhibition was postponed from July to October at the artists' request (this is discussed in more detail in several comments); it takes time to build up collaborations and trust, to draw closer and to stand back. When October came, the scientific side seemed to be rather happy with the artistic work while the artists themselves were not convinced that the pieces produced to meet the exhibition deadline met their own standards of quality. While some argued that the context of the exhibition should speak of what happened between artists and researchers, others were strongly opposed to the idea suggesting that people may approach the event with a "look for the science in the art"-attitude. One of the artists fiercely rebutted attempts to contextualise the work in order to make the overall project and link to climate research visible arguing that contemporary art has to be "unwieldy and unapproachable as much as possible" in order to be of artistic quality. There was a telling controversy on how explicit speakers and programme should show up on the flyer to promote the exhibition and symposium with the artists venting that we spoon-feed our scientists with ready-made information and one academic colleague commenting that you "always need a second degree to make sense of a HFBK flyer" (this anecdote is also discussed in Werner Krauß' text).

Despite the differences and scope for tensions that became visible in everyone's "self-identification through the other", the open-mindedness of both artists and researchers throughout the process was impressive. Both sides have met being foreign to one another's business with curiosity. They showed deep respect for each other's craft and skills and acknowledged one another's passion for doing what they do. It was the methodological dimension of the research in particular that caught the attention of the visiting artist researchers. Artistic and scientific research found common ground in focusing on methodologies: the use of analogies and metaphors (see the art work and comment by Laura Reichwald), conventions of representations such as "the colours we always use" and formats of presentations ("picture frames are petty bourgeois") were common in both artistic and scientific practice. Students recontextualised elements of the scientific method such as systematic procedures of selection and elimination of errors and experimentally tested prototypes (Schümeyer, see picture in Frauke Fesers comment). This was certainly a spark for the scientists to rethink their methods and practices, as Frauke Feser's paper testifies. In a recent review, "seeing more and differently" has come out top at a list of artistic impact on organisational environments in 
general [Berthoin Antal and Strauß, 2013]. It is the overall message of this set of comments, that encounters of art and science indeed have this potential.

\section{References}

Berthoin Antal, A. and Strauß, A. (2013). Artistic interventions in organisations: Finding evidence of values-added. Creative Clash Report. WZB, Berlin, Germany.

Reichle, I. and Rösl, F. (2010). 'Wissenschaft und Kunst. Eine interdisziplinäre Annäherung'. Gegenworte 23 (20), pp. 12-15.

Stehr, N. and von Storch, H. (1995). 'The social construct of climate and climate change'. Climate Research 5, pp. 99-105.

Stettler, R. (2010). 'Perception - Translation - Transformation'. In: Artists in labs. Vol.I: processes of inquiry. Ed. by J. Scott. Wien/New York: Springer, pp. 34-42.

Webster, S. (2006). 'Art, Science and the Public'. In: Engaging science. Thoughts, deeds, analysis and action. Ed. by J. Turney. London, U.K.: Wellcome Trust, pp. 74-79.

Wienroth, M. and Goldschmidt, P. (forth). 'Facilitating creativity in art-science. A methodological experiment'. accepted for publication in Leonardo. URL: http://www .academia.edu/7211104/Facilitating \_creativity \_in\_artscience.\_A \_methodological\_experiment (visited on 10th December 2014).

\section{Author}

Simone Rödder, Dr. phil. nat., currently heads the research group "Understanding Science in Interaction" at the University of Hamburg's climate cluster CliSAP. She studied biology, mathematics and science communication in Mainz and Glasgow and holds a PhD in sociology from the University of Bielefeld. Her main research interests are sociology of science, science communication and science journalism. She recently published "Science Media Centres and Public Policy" in Science and Public Policy (2014, DOI: 10.1093/scipol/scu057) and co-edited "The Sciences Media Connection - Public Communication and its Repercussions", Sociology of the Sciences Yearbook, volume 28, Springer, Dordrecht/Heidelberg/London/New York. More textual and visual information on the artwork produced by the "visiting artist researchers" in the course of the project can be found online at http:/ / www.clisap.de/ research/ia:-integrated-activities/ia-4:-understanding-science-in-interaction$\% 28$ usi\%29/visiting-artist-researchers-1. E-mail: simone.roedder@uni-hamburg.de.

\section{How to cite}

Rödder, S. (2015). 'Climate sciences meet visual arts'. JCOM 14 (01), C01. 